\title{
Removal of methyl orange by heterogeneous fenton process using iron dispersed on alumina pillared bentonite pellet
}

\author{
Ngo Thi Thuan ${ }^{1, *}$, Tran Tien Khoi ${ }^{1}$, Nguyen Thi My Chi ${ }^{2}$, Nguyen Ngoc Vinh ${ }^{1}$
}

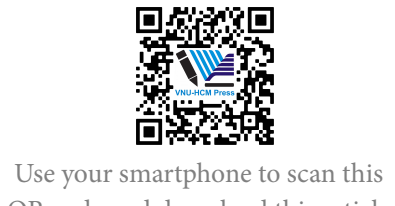

QR code and download this article
${ }^{1}$ Department of Environmental Engineering, International University, Vietnam National University Quarter 6, Linh Trung Ward, Thu Duc District, Ho Chi Minh City, Viet Nam

${ }^{2}$ Faculty of Environment, University of Science, Vietnam National University 227, Nguyen Van Cu Street, 4th Ward, District 5, Ho Chi Minh City, Viet Nam

\section{Correspondence}

Ngo Thi Thuan, Department of Environmental Engineering, International University, Vietnam National University Quarter 6, Linh Trung Ward, Thu Duc District, Ho Chi Minh City, Viet Nam

Email: ntthuan@hcmiu.edu.vn

\section{History}

- Received: 2020-04-16

- Accepted: 2020-06-12

- Published: 2020-06-30

DOI : 10.32508/stdj.v23i2.2139

\section{Check for updates}

\section{Copyright}

(c) VNU-HCM Press. This is an openaccess article distributed under the terms of the Creative Commons Attribution 4.0 International license.

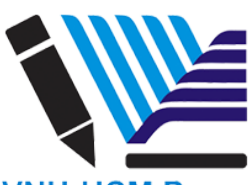

VNU-HCM Press

\begin{abstract}
Introduction: Heterogeneous Fenton is one of the Advanced Oxidation Processes (AOPs) and has been proven to be effective on azo dye degradation. However, a low-cost catalyst and factors affecting the processes of this system were further investigated. Methods: In this study, pellets of iron alumina pillared bentonite (PFeAPB) were prepared by dispersing iron ions on alumina pillared bentonite pellet. Catalyst activity and lifetime were investigated via efficiencies of Methyl Orange $(\mathrm{MO})$ decolorization and Chemical Oxygen Demand (COD) removal, a typical dye type of textile wastewater. Characteristics of the PFeAPB catalyst were examined by $X$-ray diffraction (XRD), Brunauer-Emmett-Teller (BET) surface area, and X-ray fluorescence (XRF). Results: Results of batch experiments showed that specific surface area of the PFeAPB catalyst was $111.22 \mathrm{~m}^{2} / \mathrm{g}$ higher than its precursor by 2 times $\left(57.79 \mathrm{~m}^{2} / \mathrm{g}\right)$. Goethite, Hematite and Maghemite phases with approximately $11.5 \%$ of iron elements containing in the catalyst were detected via XRD and XRF. Experimental conditions of $\mathrm{pH}$, initial $\mathrm{MO}$ solution, Hydrogen Peroxide concentration, reaction time and catalyst loading were $2.0 \pm 0.1,12.7 \mathrm{mmol} / \mathrm{L}, 150 \mathrm{~min}$ and $20 \mathrm{~g} / \mathrm{L}$, respectively, to achieve $88.68 \pm$ $5.69 \%$ of $\mathrm{MO}$ decolorization and $50.27 \pm 6.05 \%$ of COD removal while dissolved iron in this heterogeneous Fenton process was below standard limit ( 2 ppm). Catalyst activity decreased by $5.22 \%$ in decolorization efficiency after the two first reusages. Conclusion: These primary results showed the potential of applying PFeAPB catalyst in heterogeneous Fenton process with low iron leaching into water.

Key words: Heterogeneous Fenton Catalyst, Alumina Pillared Bentonite, Pellet, Methyl Orange, Textile Wastewater
\end{abstract}

\section{INTRODUCTION}

Textile is a main export industry in Vietnam and its wastewater has been listed as difficult-to-degrade wastewater. Among several physical, chemical and biological processes, adsorption has been proven as a widely used, effective method to decolorize dye in textile effluent. However, pollutants in dye wastewater are adsor ed on the adsorbent and concentrated into a smaller volume but not degraded. Advanced Oxidation Processes (AOPs) have been proven worldwide as efficient methods in dye wastewater treatment due to high oxidation of active radicals and mineralization capability to persistent organic pollutants (such as azo dyes into $\mathrm{CO}_{2}$ and $\mathrm{H}_{2} \mathrm{O}$ ). Thus, homogeneous Fenton processes are commonly applied to treat textile wastewater. However, these processes still have some disadvantages of iron treatment, sludge, and strict operation under acidic condition.

Heterogeneous Fenton processes have been introduced to overcome disadvantages of homogeneous Fenton processes. These processes apply iron catalysts which are immobilized on the surface of the adsor- bent and combined with hydrogen peroxide $\left(\mathrm{H}_{2} \mathrm{O}_{2}\right)$ to generate hydroxyl radicals $(\cdot \mathrm{OH})^{1,2}$, thus possibly minimizing iron leaching into water and operating under less acidic condition, enabling the catalyst to be reused and recycled. Bentonite clay has been used as an adsorbent and has gained much attention in environmental remediation due to iron content in clay, its low cost, its abundance, and ion-exchange capability, while still having low specific surface area ${ }^{3,4}$. Specific surface area of bentonite clay can be increased by intercalating inorganic/organic cations into expandable clay layers (so-called cation pillared bentonite). They are fabricated by cation exchange with polyoxycations of silica-alumina layers, then calcinated ${ }^{5,6}$. Among several cations to be pillared into clay, polycations of aluminum are preferred due to the well-known structure, synthesis conditions and stabilities ${ }^{7}$. In addition, alumina pillared clays give much higher surface Lewis acidity than their precursor ${ }^{6,8}$. Hence, alumina pillared bentonite may be used as a good supporter to be impregnated with irons which are active sites of heterogenous Fenton catalysts.

Cite this article : Thuan NT, Khoi TT, Chi NT M, Vinh N N. Removal of methyl orange by heterogeneous fenton process using iron dispersed on alumina pillared bentonite pellet. Sci. Tech. Dev. J.; 23(2):555-563. 
So far there are very few investigations of iron dispersed on alumina pillared bentonite used as heterogeneous Fenton catalyst for environmental remediation. Some studies focus on iron pillared bentonite as Fenton catalysts for degradation of cinnamic acid ${ }^{9}$, or dyestuff with UV light assistance ${ }^{10}$. However, researchers focus on powder type which cannot be used in a continuous system due to system clogging iron leaching into water of this catalyst as well as dye removal have not been investigated. Iron phases of this Fenton catalyst can leach into water possibly due to a poor supporter, especially in relatively acidic conditions. Therefore, a heterogeneous Fenton catalyst based on alumina pillared bentonite pellet was examined. The objective of this study was to investigate the reactivity of the PFeAPB catalyst during heterogeneous Fenton process for Methyl Orange (MO) removal from water.

\section{MATERIALS-METHODS}

\section{Materials}

A commercial clay product, bentonite powder, was purchased from a local company in Vietnam (Minh Ha Bentonite Mineral Joint Stock Company, Phan Thiet Province, Viet Nam); iron catalyst was prepared from ferric nitrate nonahydrate $\left(\mathrm{Fe}\left(\mathrm{NO}_{3}\right)_{3} .9 \mathrm{H} 2 \mathrm{O}\right.$; alumina pillared in clay was prepared from aluminum nitrate nonahydrate $\left(\mathrm{Al}\left(\mathrm{NO}_{3}\right)_{3} \cdot 9 \mathrm{H}_{2} \mathrm{O}\right)$; sodium hydroxide was purchased from Sigma-Aldrich Chemical Co. (St. Louis, MO, USA), hydrogen peroxide ( $>30$ wt.\%) and hydrochloric acid (37\%) were purchased from Fisher Scientific (UK).

\section{Catalyst preparation}

Inorganic pillaring technique has been reported previously $5,6,11,12$ and was adapted as follows: the bentonite powder was sieved with $2 \mathrm{~mm}$ to remove all big contaminants, then added into $\mathrm{Al}^{3+}$ solution to become alum-bentonite slurry. The slurry was stirred vigorously in 1 hour and left to age for 24 hours under ambient conditions. The alum-bentonite after aging was centrifuged and compacted into pellet shape (3 mm of diameter, $2-3 \mathrm{~cm}$ of length). This pellet was dried at $105^{\circ} \mathrm{C}$ for 12 hours and calcinated at $600^{\circ} \mathrm{C}$ to form the so-called pellet of alumina pillared bentonite (PAPB). $\mathrm{Fe}\left(\mathrm{NO}_{3}\right)_{3} .9 \mathrm{H}_{2} \mathrm{O} 1 \mathrm{M}$ with $10 \%$ of $\mathrm{HNO}_{3}$ solution was impregnated on the surface of PAPB for 4 hours and dried at $105^{\circ} \mathrm{C}$ for 15 hours, and finally baked at $350^{\circ} \mathrm{C}$ for 4 hours. The final product after iron impregnation was referred to as the pellet of iron alumina pillared bentonite (PFeAPB) (Figure 1).

\section{Experimental procedure}

The Fenton reactor was a $250 \mathrm{~mL}$ beaker filled with $100 \mathrm{~mL}$ of MO solution and placed in a magnetic stirring machine. The initial $\mathrm{pH}, \mathrm{H}_{2} \mathrm{O}_{2}$ concentration, $\mathrm{MO}$ concentration and catalyst loading were as follows: $3.0 \pm 0.1,12.7 \mathrm{mmol} / \mathrm{L}, 100 \mathrm{ppm}$ and $20 \mathrm{~g} / \mathrm{L}$, respectively; the reaction mixture was constantly stirred at $200 \mathrm{rpm}$ for $120 \mathrm{~min}$. Samples of the reaction mixture were taken with syringe at selected time intervals and then increased to $\mathrm{pH} \sim 10$ with $\mathrm{NaOH} 2 \mathrm{~N}$, and finally filtered through a $0.45 \mathrm{~mm}$ membrane for analysis. Each experiment was repeated 3 times. The mean value and standard deviation $( \pm$ SD) of three replicated results in each experiment were calculated and presented.

The used PFeAPB catalyst was washed with distilled water and dried at $105^{\circ} \mathrm{C}$ in an oven for $5 \mathrm{~h}$. These regenerated pellets were used to investigate catalyst reusability and stability.

\section{Analytical methods}

The UV-VIS spectra of MO were recorded from 200 to $700 \mathrm{~nm}$ using a UV-VIS spectrophotometer with a spectrophotometric quartz cell and its concentration was measured at the maximum wavelength. Chemical Oxygen Demand (COD) and total ferrous ions were determined by bichromate and 1,10-phenanthroline methods, respectively, according to the Standard Methods for the examination of water and wastewater $^{13}$.

Degradation of MO was investigated via MO decolorization (MO removal) and COD removal efficiency:

$$
M O(\%)=\left[\frac{C_{0}-C_{t}}{C_{0}}\right] \times 100
$$

Where $\mathrm{C}_{o}(\mathrm{ppm})$ is the $\mathrm{MO}$ initial concentration and initial COD, and $\mathrm{C}_{t}$ (ppm) is the MO concentration and COD at time of withdrawal.

The catalysts were characterized by X-ray diffraction spectroscopy (XRD), X-ray fluorescence (XRF) and nitrogen adsorption/desorption isotherm by Brunauer-Emmett-Teller (BET) surface area.

\section{RESULTS}

Active phases of Fenton catalysts were examined with XRD and XFR analysis. Figure 2 shows X-ray diffraction spectra of $5 \%$ iron dispersed on the alumina pillared bentonite catalyst; there were Goethite $(\alpha$ $\mathrm{FeOOH})$, Hematite $\left(\alpha-\mathrm{Fe}_{2} \mathrm{O}_{3}\right)$ and Maghemite $(\gamma$ $\mathrm{Fe}_{3} \mathrm{O}_{4}$ ) found in the PFeAPB catalyst. Element compositions of the catalyst and its precursor were obtained by XRF analysis and are shown in Table 1. Notably, Si, Al, Fe, Ca and Mn were five elements found 


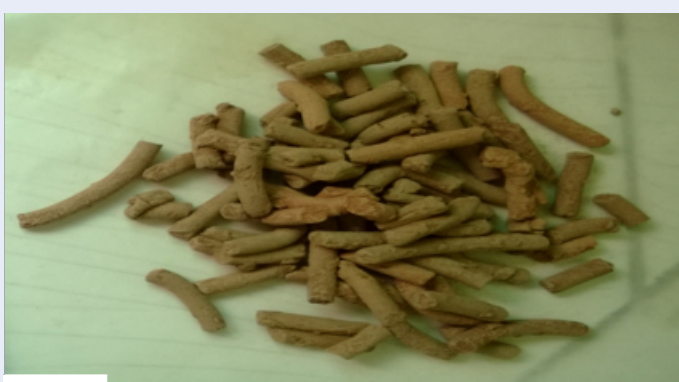

(a)

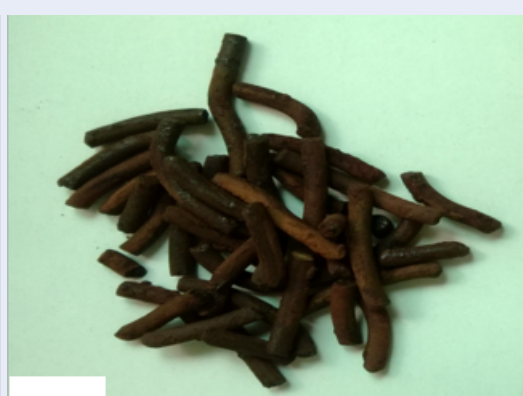

(b)

Figure 1: Configuration of (a) PAPB and (b) PFeAPB catalysts.

in both $\mathrm{PFeAPB}$ catalyst and its precursor in the range of 0.09 to $51.0 \%$. Si, $\mathrm{Al}$ and $\mathrm{Fe}$ contents in the PFeAPB catalyst accounted for $49.1 \%, 21.1 \%$ and $11.5 \%$ of the total content, while their presence in its catalyst precursor accounted for $51.0 \%, 12.2 \%$ and $6.95 \%$, respectively.

Performance of PFeAPB catalyst in the heterogeneous Fenton system was evaluated by comparing removal efficiencies among $\mathrm{H}_{2} \mathrm{O}_{2}$, PAPB, PAPB $+\mathrm{H}_{2} \mathrm{O}_{2}$, and $\mathrm{PFeAPB}+\mathrm{H}_{2} \mathrm{O}_{2}$ systems with time; the data are presented in Figure 3. The results showed that increasing time from 15 to 180 minutes led to enhanced decolorization efficiency of MO from $2.09 \pm 0.66 \%$ to $75.23 \pm 5.35 \%$, respectively, and in a sequence of $\mathrm{H}_{2} \mathrm{O}_{2}<\mathrm{PAPB}<\mathrm{PAPB}+\mathrm{H}_{2} \mathrm{O}_{2}<\mathrm{PFeAPB}+\mathrm{H}_{2} \mathrm{O}_{2}$.

Iron element was likely a main contribution to the heterogeneous Fenton processes. The effects of the iron contents impregnated in the catalyst were evaluated and recorded in Figure 4. An increase from 5 to $20 \%$ of iron impregnated in the PFeAPB catalyst enhanced MO decolorization efficiency from $68.50 \pm$ $6.59 \%$ to $82.10 \pm 7.02 \%$, respectively. The dissolved iron started to leach into the water and its level was over the standard limit (2 ppm) when $15 \%$ of iron ions were dispersed in the catalyst.

The $\mathrm{pH}$ effect on leaching of iron ions and $\cdot \mathrm{OH}$ production on MO decolorization was depicted in Figure 5. The results in Figure 5 indicate that the high decolorization efficiencies of $\mathrm{MO}$ were achieved at $\mathrm{pH}$ $=2(80.32 \pm 5.26 \%)$ and $\mathrm{pH}=3(69.10 \pm 4.26 \%)$. The other $\mathrm{pH}$ values yielded around $47.20-52.05 \%$ of decolorization efficiencies.

The $\mathrm{H}_{2} \mathrm{O}_{2}$ concentrations were examined in a range of $0-50.8 \mathrm{mmol} / \mathrm{L}$. The results of the effect of $\mathrm{H}_{2} \mathrm{O}_{2}$ are shown in Figure 6 a, b. When $\mathrm{H}_{2} \mathrm{O}_{2}$ concentration was increased from 0 to $12.7 \mathrm{mmol} / \mathrm{L}$, the decolorization efficiencies of MO increased to $75.69 \pm 4.35 \%$.
This efficiency decreased when $\mathrm{H}_{2} \mathrm{O}_{2}$ concentration was over $12.7 \mathrm{mmol} / \mathrm{L}$.

The effect of reaction time on MO decolorization, COD removal, and iron leaching in water are shown in Figure 7. MO decolourization and COD removal efficiencies were achieved from $60.45 \pm 6.26 \%$ to $88.68 \pm 5.69 \%$ and $30.32 \pm 3.69 \%$ to $50.27 \pm 6.05 \%$, respectively, in the range of $15-150 \mathrm{~min}$.

Reusability and stability of the PFeAPB catalyst were investigated and shown in Figure 8. The repeatability of catalyst reactivities for the first two runs was achieved below 5.22\%. Decolorization efficiencies were dropped to $16.39 \%$ and $39.08 \%$ in the $3^{\text {rd }}$ and $4^{\text {th }}$ run of the experiments.

\section{DISCUSSION}

\section{Catalyst characterization}

Iron active phases observed at around $21.23^{\circ}, 33.1^{\circ}$ and $35.6^{\circ}$ were Goethite $(\alpha-\mathrm{FeOOH})$, Hematite $\left(\alpha-\mathrm{Fe}_{2} \mathrm{O}_{3}\right)$ and Maghemite $\left(\gamma-\mathrm{Fe}_{3} \mathrm{O}_{4}\right)$, respectively, with increasing intensity (Figure 2). Hematite and Maghemite phases are proposed to be the active sites of heterogenous Fenton catalysts ${ }^{14,15}$.

The bentonite is a natural clay with $2: 1$ silicate layer which is featured with hydroxide aluminium phyllosilicates. Aluminum (Al) and Silicon (Si) elements are dominant in bentonite clay. Change of PFeAPB composition was indicated by successful intercalation and impregnation of aluminum and iron ions into Bentonite clay (Table 1). The specific surface area of the pillared catalysts increased dramatically, from $57.79 \mathrm{~m}^{2} / \mathrm{g}$ to $111.22 \mathrm{~m}^{2} / \mathrm{g}$, compared to the precursor clay. The alumina pillared into the Bentonite layers increased the specific surface area and adsorption capabilities due to the wider basal space among the 2 silicate layers. These results support many previous observations that the specific surface area increases when the precursor clay is pillared with cation 


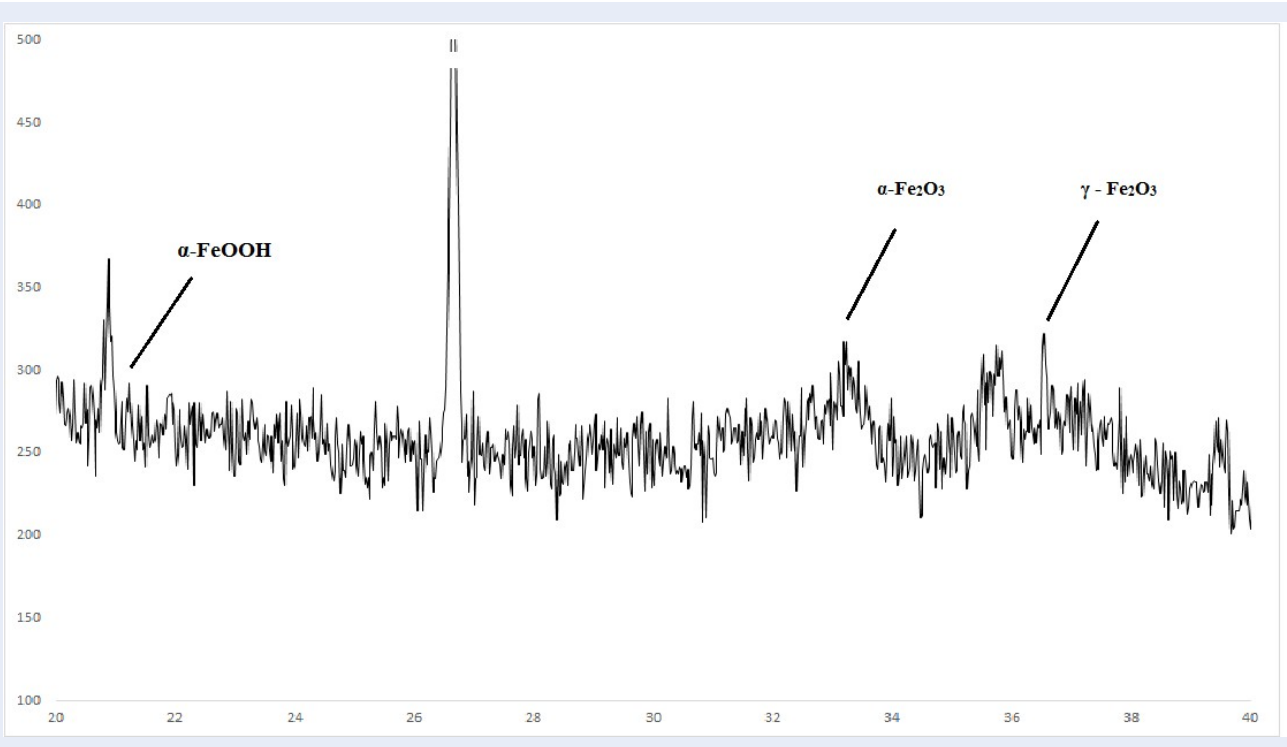

Figure 2: XRD pattern of PFeAPB catalyst with $5 \%$ of iron loading.

ions ${ }^{8-10,16,17}$. Iron content in the PFeAPB catalyst increased from $6.95 \%$ to $11.5 \%$ due to introducing $5 \%$ iron into the catalyst. Loss of $0.45 \%$ iron may come from preparation and vaporization during calcination.

\section{Evaluation on performance of heteroge- nous Fenton process}

The results in Figure 3 were attributed to two characteristics including clay adsorption of PAPB and oxidation of $\mathrm{H}_{2} \mathrm{O}_{2}$, as well as hydroxyl radical $(\cdot \mathrm{OH})$. Decolorization efficiencies of $\mathrm{H}_{2} \mathrm{O}_{2}$ oxidation and PAPB adsorption were $6.04 \pm 0.78 \%$ and $18.12 \pm 1.49 \%$ at $120 \mathrm{~min}$, respectively. Synergetic effect of PAPB and $\mathrm{H}_{2} \mathrm{O}_{2}$ yielded $40.36 \pm 3.27 \%$ of $\mathrm{MO}$ conversion. Decolorization efficiency of MO was increased from $40.36 \pm 3.27 \%$ to $71.50 \pm 5.69 \%$ when the iron catalyst was added into PAPB. This was explained by increasing iron content in the catalyst $(\sim 4.55 \%)$ and by $\mathrm{H}_{2} \mathrm{O}_{2}$ which releases $\cdot \mathrm{OH}$ in the system; these steps may occur in Equation (1) and (2).

$\mathrm{FeOOH}_{(s)}+2 \mathrm{H}^{+}+\frac{1}{2} \mathrm{H}_{2} \mathrm{O}_{2} \rightarrow \mathrm{Fe}^{2+}+\frac{1}{2} \mathrm{O}_{2}+2 \mathrm{H}_{2} \mathrm{O}$ (1) $\mathrm{Fe}_{2} \mathrm{O}_{3(s)}+6 \mathrm{H}^{+} \rightarrow 2 \mathrm{Fe}^{2+}+3 \mathrm{H}_{2} \mathrm{O}(1-1)$

$\mathrm{Fe}_{3} \mathrm{O}_{4(s)}+8 \mathrm{H}^{+} \rightarrow 3 / 2 \mathrm{Fe}^{3+}+3 / 2 \mathrm{Fe}^{2+}+4 \mathrm{H}_{2} \mathrm{O}$. (1-2)

$\mathrm{Fe}^{2+}+\mathrm{H}_{2} \mathrm{O}_{2} \rightarrow \mathrm{Fe}^{3+}+\mathrm{OH}^{-}+{ }^{\bullet} \mathrm{OH}$ (2)

\section{Effect of iron content impregnated into the PFeAPB catalyst}

Decolorization efficiency increased from $68.50 \pm 6.59 \%$ to $82.10 \pm 7.02 \%$ when the impregnated iron amount was enhanced from $5 \%$ to $20 \%$ because iron phases are supposedly the main active catalysts of PFeAPB materials and can provide highly reactive radicals $\left(\cdot \mathrm{OH}, \mathrm{HO}_{2}{ }^{\circ}\right)$ for $\mathrm{MO}$ decolorization via Fenton processes, according to Equations (2) to (8) :

$\mathrm{Fe}^{2+}+\mathrm{H}_{2} \mathrm{O}_{2} \rightarrow \mathrm{Fe}^{3+}+{ }^{\bullet} \mathrm{OH}+\mathrm{OH}^{-}(2)$

$\mathrm{Fe}^{2+}+{ }^{\bullet} \mathrm{OH} \rightarrow \mathrm{Fe}^{3+}++\mathrm{OH}^{-}(3)$

$\mathrm{Fe}^{3+}+\mathrm{H}_{2} \mathrm{O}_{2} \rightarrow \mathrm{Fe}^{2+}+\mathrm{HO}_{2}^{\bullet}+\mathrm{H}^{+}(4)$

$\mathrm{Fe}^{2+}+\mathrm{HO}_{2}^{\bullet} \rightarrow \mathrm{Fe}^{3+}+\mathrm{HO}_{2}^{\bullet}(5)$

$\mathrm{Fe}^{3+}+\mathrm{HO}_{2}^{\bullet} \rightarrow \mathrm{Fe}^{2+}+\mathrm{O}_{2}+\mathrm{H}^{+}(\mathbf{6})$

$\mathrm{C}_{14} \mathrm{H}_{13} \mathrm{~N}_{3} \mathrm{NaO}_{3} \mathrm{SH}+\bullet \mathrm{OH} \rightarrow \mathrm{H}_{2} \mathrm{O}+\mathrm{R}^{\bullet}(7)$

$\mathrm{R}^{\bullet}+{ }^{\bullet} \mathrm{OH} \rightarrow \mathrm{H}_{2} \mathrm{O}+$. by products (8)

However, a small change of MO decolorization efficiencies $(80.20 \pm 5.69 \% \& 82.10 \pm 7.02 \%)$ at $15 \%$ and $20 \%$ of impregnated irons was possibly due to the

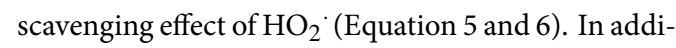
tion, dissolved irons of $2.01 \pm 0.48 \mathrm{ppm}$ were observed at $15 \%$ of impregnated irons. The amount of impregnated irons in the catalyst should be below $10 \%$ to avoid iron leaching and to achieve the national standard limit (2 mg/L). However, change of iron contents in the catalysts need to be further investigated with XRD spectra to confirm reactivity of iron active phases during the heterogeneous Fenton processes.

\section{Effect of pH on decolorization efficiency}

The active phases of iron oxide, such as goethite $(\alpha$ $\mathrm{FeOOH})$, hematite $\left(\alpha-\mathrm{Fe}_{2} \mathrm{O}_{3}\right)$ and maghemite $(\gamma$ $\mathrm{Fe}_{2} \mathrm{O}_{3}$ ) of the PFeAPB, tend to be dissolved in acidic condition to become ferrous and ferric ions, according to Equations 1, 9 and 10. These ferrous and ferric ions promoted ${ }^{\bullet} \mathrm{OH}$ radicals to discolor MO. Acidic 


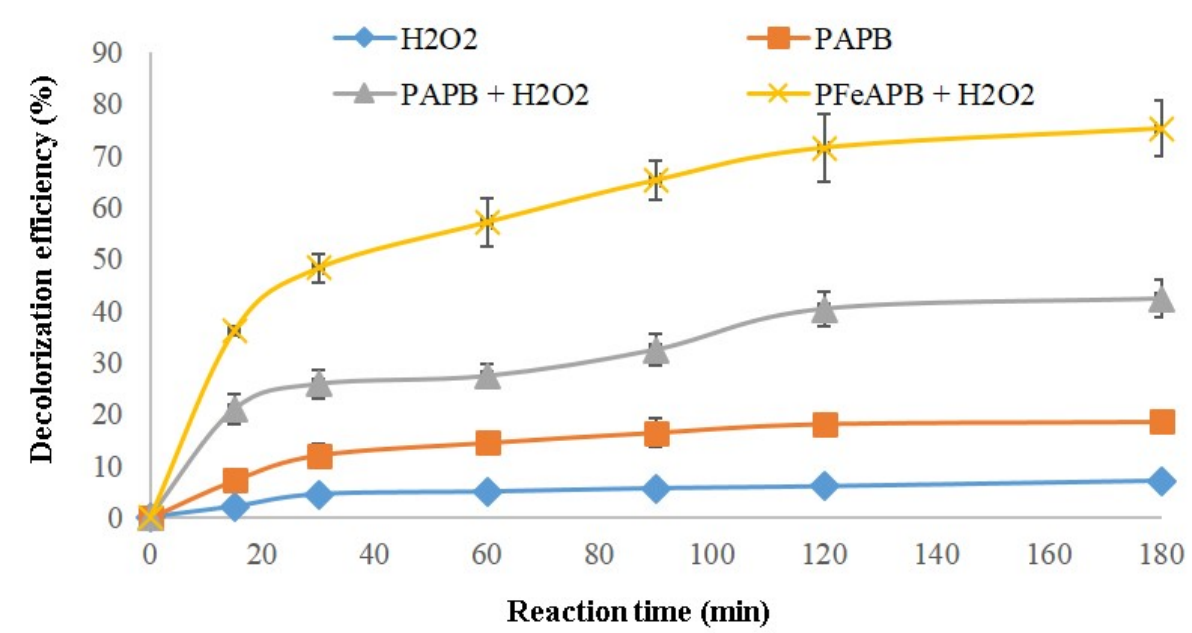

Figure 3: Decolorization efficiency ( \pm SD) of $\mathbf{M O}$ under various systems. Experimental conditions: $\mathrm{pH}=3.0 \pm$ $0.1,[\mathrm{MO}]=100 \mathrm{mg} / \mathrm{L},\left[\mathrm{H}_{2} \mathrm{O}_{2}\right]=12.7 \mathrm{mM}$, catalyst loading: $20 \mathrm{~g} / \mathrm{L}$.

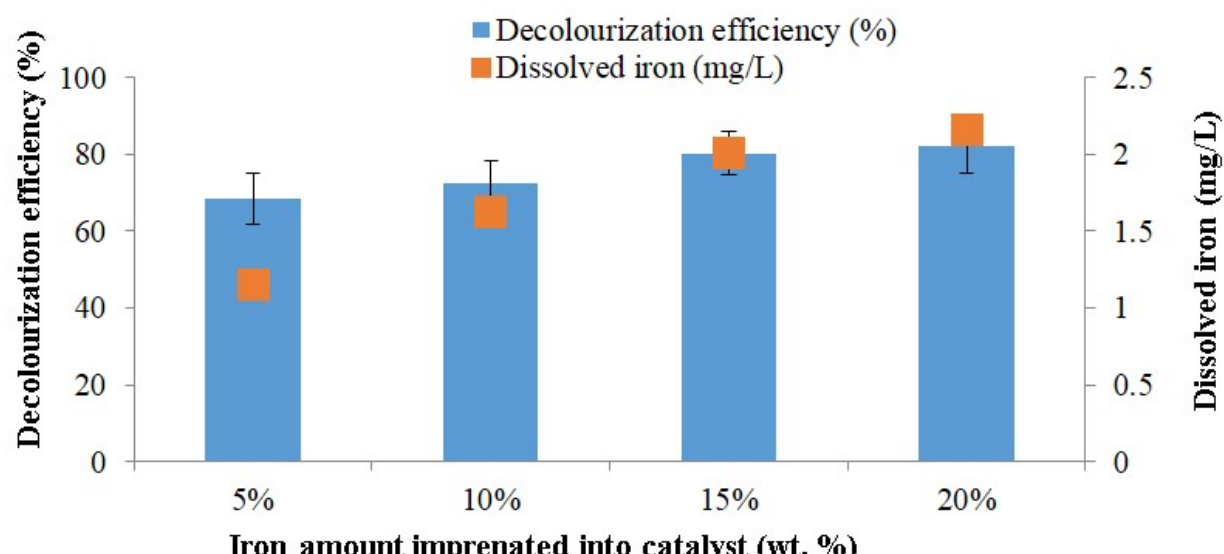

Figure 4: Effect of iron contents impregnated on MOdecolorization efficiency ( \pm SD) and dissolved iron. Experimentalconditions: $\mathrm{pH}=3.0 \pm 0.1,[\mathrm{MO}]=100 \mathrm{mg} / \mathrm{L}$, $\left[\mathrm{H}_{2} \mathrm{O}_{2}\right]=12.7 \mathrm{mM}$, catalyst loading: $20 \mathrm{~g} / \mathrm{L}$, reaction time $=120$ $\min$.

$\mathrm{pH}$ values also shift the equilibrium of Equation 2 to the right which promotes $\mathrm{OH}$ radical formation; the high decolorization efficiencies of $\mathrm{MO}$ were achieved at $\mathrm{pH}=2(80.32 \pm 5.26 \%)$ and $\mathrm{pH}=3(69.10 \pm 4.26 \%)$. However, if the soluble constant of $\mathrm{Fe}(\mathrm{OH})_{3}$ is theoretically $2.79^{\star} 10^{39}$, precipitation of $\mathrm{Fe}(\mathrm{OH})_{3}$ starts to occur at approximate $\mathrm{pH}=4.0$, thus resulting in decreasing decolorization efficiency $(52.05 \pm 5.96 \%)$ as expected, thus preventing the Fenton process (Equations $1 \& 2$ ). When hydrogen ions in the system are too high $(\mathrm{pH}=1)$, these ions may become scavengers of $\bullet \mathrm{OH}$ radicals (Equation 11), inducing MO decol- orization capability $(50.10 \pm 5.23 \%)$. These results are relatively comparable to other studies ${ }^{1,2,9}$ and indicate a wider range of $\mathrm{pH}$ in the heterogeneous Fenton system. A pH=2 was chosen to achieve the highest efficiency for further investigation in this study.

$\mathrm{FeOOH}_{(s)}+2 \mathrm{H}^{+}+\frac{1}{2} \mathrm{H}_{2} \mathrm{O}_{2} \rightarrow \mathrm{Fe}^{2+}+\frac{1}{2} \mathrm{O}_{2}+2 \mathrm{H}_{2} \mathrm{O}(\mathbf{1})$

$\mathrm{Fe}_{2} \mathrm{O}_{3(s)}+6 \mathrm{H}^{+} \rightarrow 2 \mathrm{Fe}^{3+}+3 \mathrm{H}_{2} \mathrm{O}(9)$

$\mathrm{Fe}_{3} \mathrm{O}_{4(s)}+8 \mathrm{H}^{+} \rightarrow 3 / 2 \mathrm{Fe}^{3+}+3 / 2 \mathrm{Fe}^{2+}+4 \mathrm{H}_{2} \mathrm{O}(\mathbf{1 0})$

$\mathrm{H}^{+}+{ }^{\bullet} \mathrm{OH}+\mathrm{e}^{-} \rightarrow \mathrm{H}_{2} \mathrm{O}(\mathbf{1 1})$ 


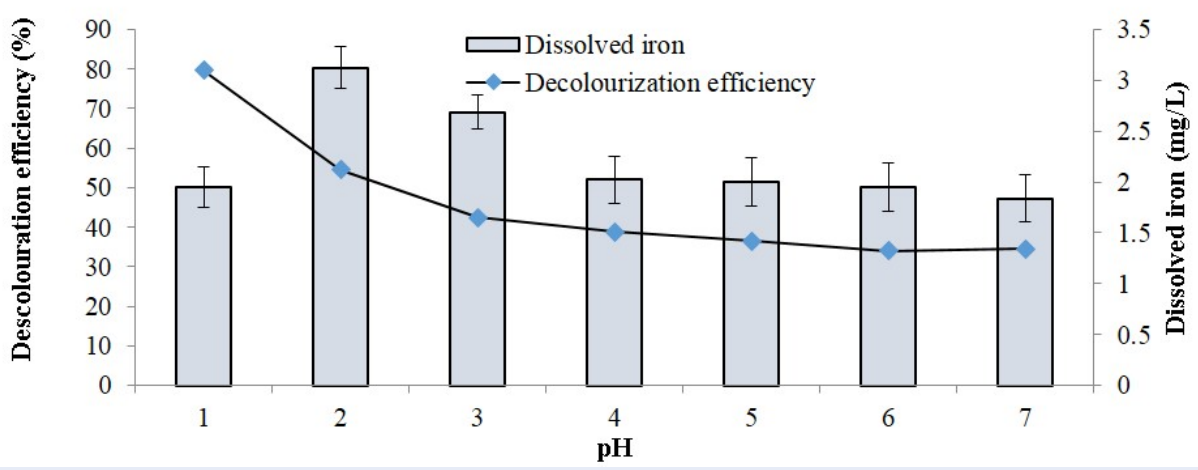

Figure 5: Effect of pH on MOdecolorization efficiency ( \pm SD) and dissolved iron. Experimental conditions: $[\mathrm{MO}]=100 \mathrm{mg} / \mathrm{L}$, $\left[\mathrm{H}_{2} \mathrm{O}_{2}\right]=12.7 \mathrm{mM}$, catalyst loading: $20 \mathrm{~g} / \mathrm{L}$, reaction time $=120 \mathrm{~min}$.

\section{Effect of $\mathrm{H}_{2} \mathrm{O}_{2}$ concentration}

Effect of $\mathrm{H}_{2} \mathrm{O}_{2}$ concentration on $\mathrm{MO}$ decolorization efficiencies are contributed by highly oxidation capability of $\mathrm{H}_{2} \mathrm{O}_{2}$ species as well as the release of ${ }^{\bullet} \mathrm{OH}$ and $\mathrm{HO}_{2}$ radicals during reactions between ferrous and ferric ions and $\mathrm{H}_{2} \mathrm{O}_{2}$ (Equations 2 \& 4). However, when the $\mathrm{H}_{2} \mathrm{O}_{2}$ amount is increased over 12.7 $\mathrm{mmol} / \mathrm{L}$, the decolorization efficiencies were dropped by $20 \%$ due to the scavenging of $\bullet \mathrm{OH}$ by $\mathrm{H}_{2} \mathrm{O}_{2}$, as shown in Equations 12 \&13.

- $\mathrm{OH}+\mathrm{O}_{2} \rightarrow \mathrm{HO}_{2}^{\bullet}+\mathrm{H}_{2} \mathrm{O}$ (12)

$\mathrm{HO}_{2}^{\bullet}+\bullet \mathrm{OH} \rightarrow \mathrm{H}_{2} \mathrm{O}+\mathrm{O}_{2} \quad(\mathbf{1 3})$

UV-VIS spectroscopy of MO before and after heterogenous Fenton reaction under different $\mathrm{H}_{2} \mathrm{O}_{2}$ concentrations are shown in Figure $\mathbf{6} \mathbf{b}$. The strongest absorbance of MO molecules was at $464 \mathrm{~nm}$. After 120 min of heterogenous Fenton reaction, this peak disappeared totally when $\mathrm{H}_{2} \mathrm{O}_{2}$ concentration was $12.7 \mathrm{mmol} / \mathrm{L}$. A new peak appeared from 232 to 239 $\mathrm{nm}$, possibly because of $\pi \rightarrow \pi^{\star}$ transition in aromatic compounds. The results indicate that decolorization of MO molecules may occur at azo site $(-\mathrm{N}=\mathrm{N}-)$ and that the peaks at $232-239 \mathrm{~nm}$ are possibly benzylamine compounds such as sulfanilic acid. This result is comparable to standard spectroscopy of pure sulfanilic acid ${ }^{15,18}$. The final products of the heterogenous Fenton processes need to be further analyzed by GC-MS.

\section{Effect of reaction time}

The relatively low decolorization efficiency (60.45 \pm $3.26 \%)$ and COD removal $(30.32 \pm 3.69 \%)$ of MO at the beginning of the heterogeneous Fenton processes (15 min) were possible due to MO molecule diffusion and adsorption on the surface of the catalysts. Once MO molecules were adsorbed on the active sites of irons, heterogenous Fenton process occurred in the presence of $\mathrm{H}_{2} \mathrm{O}_{2}$, thus increasing $\mathrm{MO}$ decolorization with time. However, this process was slowed after 120 min because the low catalytic activity, possibly relating to the formation of intermediate oxidation products which inhibited ${ }^{\bullet} \mathrm{OH}$ released at iron active sites $^{19}$.

Efficient differences between MO decolorization and COD removal efficiencies were from 30 to $40 \%$. The maximum COD removal efficiency was $50.27 \pm 6.05 \%$ at $150 \mathrm{~min}$ while the decolorization efficiency was $88.68 \pm 5.69 \%$ (Figure 7 ). These results indicate that heterogeneous Fenton processes using the PFeAPB catalysts may oxidize $\mathrm{MO}$ molecules into smaller organic molecules and partly mineralize into $\mathrm{CO}_{2}$ and $\mathrm{H}_{2} \mathrm{O}$. Mineralization of azo dyes occurred slowly compared to the decolorization processes. The COD of the MO solution cannot be removed completely, only $50.27 \pm 6.05 \%$ in $150 \mathrm{~min}$, possibly due to formation of some persistent by-products and short lifetime of radicals. Dissolved irons were increased with reaction time; however, the concentration (max. $1.13 \pm 0.068 \mathrm{ppm}$ ) was still below the national standard limit in water (2 ppm). Resistance to iron leaching into solution is possibly due to metal complexes between acid organic compounds, such as 2carboxyphenylacetic acid, phthalic acid, and oxalic acid, which are released as by-products and iron sites on the PFeAPB surface ${ }^{15}$. In addition, iron ions were properly immobilized within the interlayer space and associated with alumina pillars, thus becoming highly resistant to iron leaching ${ }^{20,21}$.

\section{Catalyst reusability and stability}

The pillared process between intercalation of aluminum and iron greatly increases accessibility of reactants and reduces their intermolecular collision 

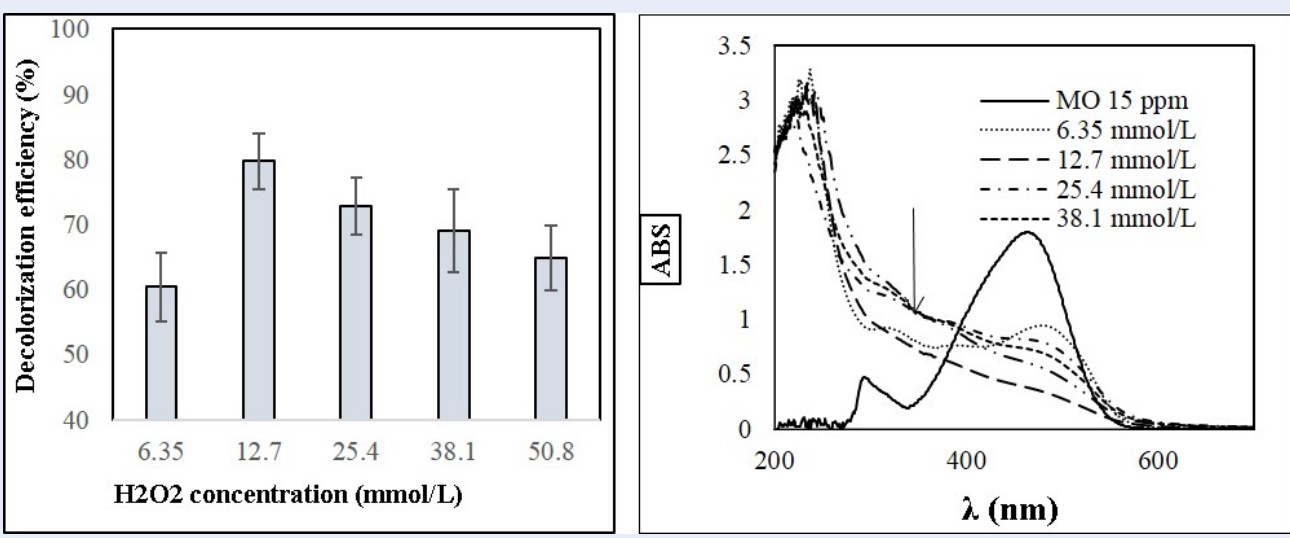

Figure 6: (a) Effect of $\mathrm{H}_{2} \mathrm{O}_{2}$ on decolorizationefficiency ( \pm SD); (b) UV-VIS spectroscopy of MO before and after heterogenous Fenton reaction. Experimental conditions:[MO] $=100 \mathrm{mg} / \mathrm{L}, \mathrm{pH}=2.0 \pm 0.1$, catalyst loading: 20 $g / L$, reaction time $=120 \mathrm{~min}$.

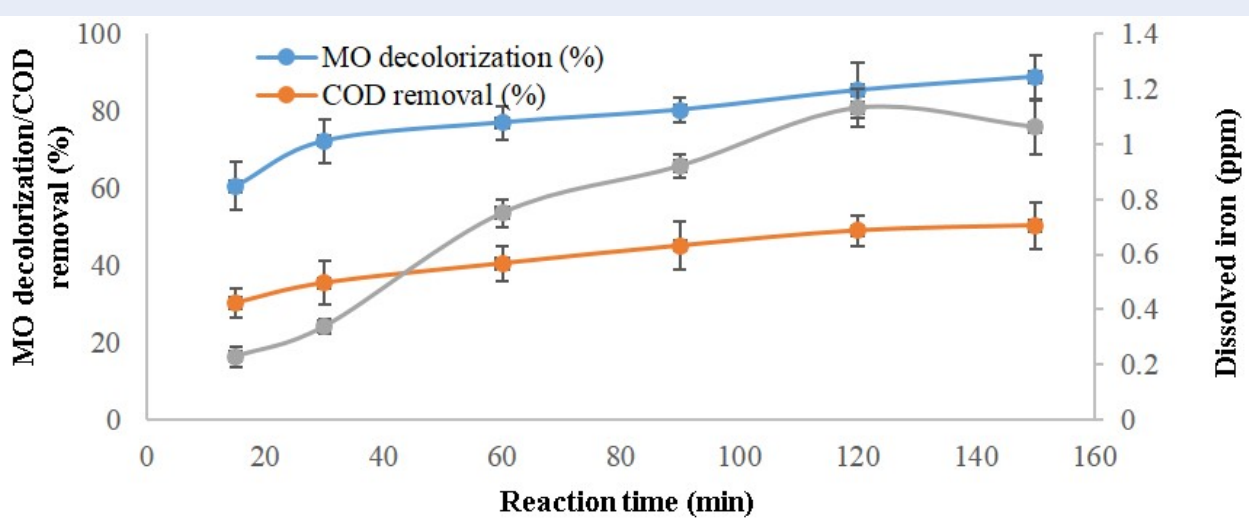

Figure 7: Effect of reaction time on performance of PFeAPB catalyst in heterogenous Fenton process (mean \pm SD). Experimental conditions: $[M O]=100 \mathrm{mg} / \mathrm{L}$, $\left[\mathrm{H}_{2} \mathrm{O}_{2}\right]=12.7 \mathrm{mM}$, catalyst loading: $20 \mathrm{~g} / \mathrm{L}, \mathrm{pH}=2 \pm 0.1$.

and competition at the catalyst sites ${ }^{22,23}$. Thus, the PFeAPB could be reused two times and yielded 5.22\% repeatability (Figure 8). The PFeAPB catalyst activity decreased after 2 runs of reusage $(16.39 \%$ and $39.08 \%$ ) - at the $3 \mathrm{rd}$ and 4 th runs- which may be attributed to iron leaching and intermediate products adsorbed on the active sites.

\section{CONCLUSIONS}

This study primarily developed a pellet type of Iron dispersed on Alumina Pillared Bentonite and investigated its capability of MO treatment from water. XRD results showed that there were $\alpha-\mathrm{FeOOH}, \alpha-\mathrm{Fe}_{2} \mathrm{O}_{3}$ and $\gamma-\mathrm{Fe}_{3} \mathrm{O}_{4}$ which were supposedly catalyst phases of the heterogeneous Fenton reaction. Because of successful intercalation of Alumina into Bentonite layers, the specific surface area was increased from 57.79 $\mathrm{m}^{2} / \mathrm{g}$ to $111.22 \mathrm{~m}^{2} / \mathrm{g}$, according to the BET results. The PFeAPB catalysts achieved $88.68 \pm 5.69 \%$ of $\mathrm{MO}$ decolorization and $50.27 \pm 6.05 \%$ of COD removal when experimental conditions of $\mathrm{pH}, \mathrm{H}_{2} \mathrm{O}_{2}$ concentration, catalyst loading, reaction time and initial $\mathrm{MO}$ concentration were $2 \pm 0.1,12.7 \mathrm{mmol} / \mathrm{L}, 20 \mathrm{~g} / \mathrm{L}, 150$ min and 100 ppm, respectively. The PFeAPB catalyst can be resistant to iron leaching with $11.5 \%$ of iron content in the catalyst and can be reused 2 times with $5.22 \%$ of repeatability, compared to the new catalyst. The study results indicate that PFeAPB can be a potential catalyst for the heterogeneous Fenton process and applied in textile wastewater with low loss of iron leaching into water. This catalyst should be further investigated in a continuous system. 


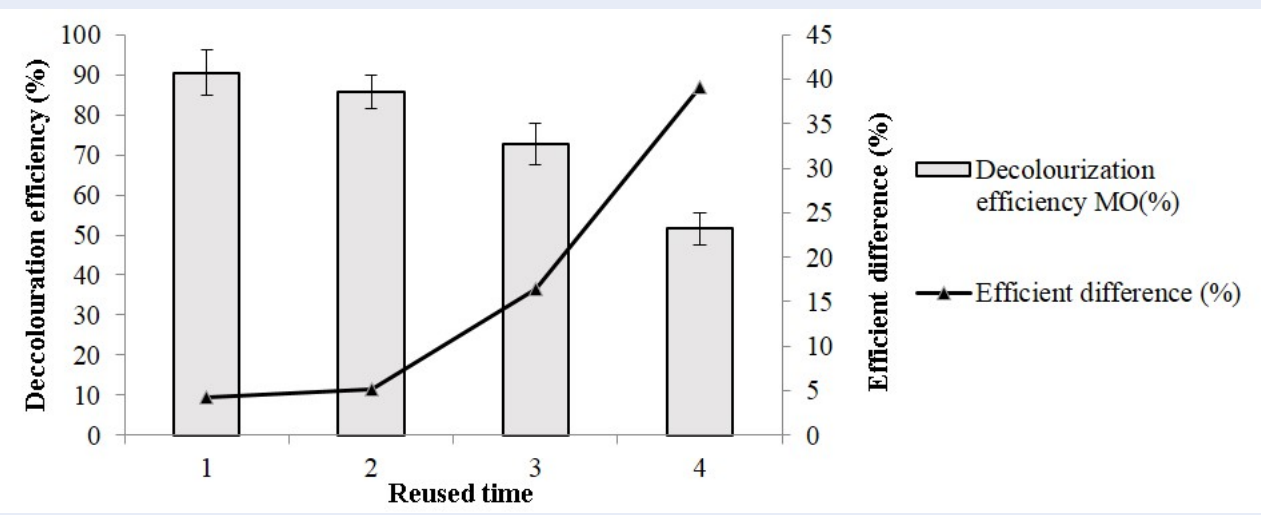

Figure 8: Reusability of PFeAPB catalyst (mean \pm SD). Experimental conditions: $[M O]=100 \mathrm{mg} / \mathrm{L},\left[\mathrm{H}_{2} \mathrm{O}_{2}\right]=12.7$ $\mathrm{mM}$, catalyst loading: $20 \mathrm{~g} / \mathrm{L}, \mathrm{pH}=2 \pm 0.1$, reaction time $=150 \mathrm{~min}$.

\section{LIST OF ABBREVIATIONS}

COD: Chemical Oxidation Demand

BET: Nitrogen adsorption/desorption isotherm

MO: Methyl Orange

XRD: X-ray diffractometer

XRF: X-ray fluorescence

PFeAPB: Pellet of iron alumina pillared bentonite

UV-VIS: Ultraviolet visible

\section{AUTHORS' CONTRIBUTIONS}

The author Ngo Thi Thuan discussed the results and wrote the manuscript. The author Tran Tien Khoi edited and revised the final manuscript. The author Nguyen Thi My Chi did the experiment. The author Nguyen Ngoc Vinh trained the instrument operations in laboratory. All authors approved the final manuscript.

\section{COMPETING INTERESTS}

The authors declare that they have no competing interests.

\section{ACKNOWLEDGEMENTS}

The authors would like to thank MSc. Le Thi Song Thao for her contribution on primarily investigation of the catalyst activity.

\section{REFERENCES}

1. Feng J, Hu X, Yue PL. Discoloration and mineralization of Orange II by using a bentonitee clay-based Fe nanocomposite film as a heterogeneous photo-Fenton catalyst. Water Research. 2015;39(1):89-96. PMID: 15607168. Available from: https://doi.org/10.1016/j.watres.2004.08.037.

2. Dung NT, Hoa PN, Huy DM, Tham NK. Magnetic Fe2MO4 (M:Fe, $\mathrm{Mn}$ ) activated carbons: Fabrication, characterization and heterogeneous Fenton oxidation of methyl Orange. Journal of Hazardous Materials. 2011;185:653 -661. PMID: 20952129. Available from: https://doi.org/10.1016/j.jhazmat.2010.09.068.
3. Churchman GJ, Gates WP, Theng BKG, Yuan G. Clays and minerals for pollution control. Development in clay science. Elsevier, The Netherlands. 2006;1:253-278. Available from: https://doi.org/10.1016/S1572-4352(05)01020-2.

4. Daou I, Zegaoui O, Chafaira R, Ahlafi H, Moussout H. Physicpchemical characterization and kinetic study of methylene blue adsorption onto a Moroccan Bentonite. International Journal of Scientific and Research Publications. 2015;5(5):1-9.

5. Gil A, Gandia LM, Vicente MA. Recent advances in the synthesis and catalytic applications of pillared clays. Catal Rev. 2000;42:145-212. Available from: https://doi.org/10.1081/CR100100261.

6. Gil A, Korili SA, Vicente MA. Recent advances in the control and characterization of the porous structure of pillared clay catalysts. Catal Rev. 2008;50:153-221. Available from: https: //doi.org/10.1080/01614940802019383.

7. Wen K, Wei J, He H, Zhu J, Xi Y. Keggin-Al30: An intercalant for Keggin-Al30 pillared montmorillonite. Applied Clay Science. 2019;180:105-203. Available from: https://doi.org/10.1016/j. clay.2019.105203.

8. Gil A, Korili SA, Trujillono, Vicente MA. Pillared clays and Related catalysts. Springer, New York. 2010;p. 23-42. Available from: https://doi.org/10.1007/978-1-4419-6670-4.

9. Tabet $D$, Saidi $M$, Houari M, Pichat $P$, Khalaf H. Fe-pillared clay as a Fenton-type heterogenous catalyst for cinnamic acid degradation. Journal of Environmental Management. 2006;80:342-346. PMID: 16546315. Available from: https: //doi.org/10.1016/j.jenvman.2005.10.003.

10. Chen J, Zhu L. Heterogenous UV-Fenton catalytic degradation of dyestuff in water with hydroxyl Fe pillared bentonite. Catalysis Today. 2007;126(3-4):463-470. Available from: https: //doi.org/10.1016/j.cattod.2007.06.022.

11. Barrault J, Abdellaoui M, Bouchoule C, Majeste A, Tatibouet $J M$, Louloudi A, et al. Catalytic wet peroxide oxidation over mixed (Al-Fe) pillared clays. Appl Catal B Environ. 2000;27:225-230. Available from: https://doi.org/10.1016/ S0926-3373(00)00170-3.

12. Barrault J, Gatineau L, Hassoun N, Bergaya F. Selective syngas conversion over mixed Al-Fe pillared Laponite clay. Energy Fuels. 1992;6:760-763. Available from: https://doi.org/10.1021/ ef00036a010.

13. American Public Health Association. Standard methods for the examination of water and wastewater; 23nd Edition. 2017;

14. Ali ME, Gad-Allah TA, Badawy MI. Heterogeneous Fenton process using steel industry wastes for methyl orange degradation. Applied Water Science. 2013;3(1):263-270. Available from: https://doi.org/10.1007/s13201-013-0078-1. 
15. Chen ZX, Jin XY, Chen Z, Megharaj M, Naidu R. Removal of methyl Orange from aqueous solution using bentonitesupported nanoscale zero-valent iron. Journal of colloid and interface science. 2011;363(2):601-607. PMID: 21864843. Available from: https://doi.org/10.1016/j.jcis.2011.07.057.

16. Luo M, Bowden D, Brimblecombe P. Catalytic property of Fe-AI pillared clay for Fenton oxidation of phenol by $\mathrm{H} 2 \mathrm{O} 2$. Applied catalysis B: Environmental. 2009;85:201-206. Available from: https://doi.org/10.1016/j.apcatb.2008.07.013.

17. Ayodele B, Lim JK, Hameed BH. Pillared montmorillonite supported ferric oxalate as heterogenous photo-Fenton catalyst for degradation of amoxicillin. Applied catalysis A: General. 2012;(413-414):201-209. Available from: https://doi.org/10. 1016/j.apcata.2011.11.023.

18. Devi LG, Kumar SG, Reddy KM, Munikrishnappa C. Photo degradation of Methyl Orange an azo dye by Advanced Fenton Process using zero valent metallic iron: Influence of various reaction parameters and its degradation mechanism. Journal of hazardous materials. 2009;164(2):459-467. PMID: 18805635. Available from: https://doi.org/10.1016/j.jhazmat. 2008.08.017.

19. Yip AC, Lam FL, Hu X. Novel bimetallic catalyst for the photoassisted degradation of Acid Black 1 over a broad range of
pH. Chemical Engineering Science. 2007;62(18-20):51505153. Available from: https://doi.org/10.1016/j.ces.2007.01 014.

20. Zhong X, Xiang L, Royer S, Valange S, Barrault J, Zhang H. Degradation of $\mathrm{Cl}$ Acid Orange 7 by heterogeneous Fenton oxidation in combination with ultrasonic irradiation. Journal of Chemical Technology and Biotechnology. 2011;86(7):970977. Available from: https://doi.org/10.1002/jctb.2608.

21. Herney-Ramirez J, Herney-Ramirez J, Vicente MA, Madeira LM. Heterogenous photo-Fenton oxidation with pillared clay catalyst for wastewater treatment: A review. Applied Catalysis B: Environmental. 2010;98:10-26. Available from: https: //doi.org/10.1016/j.apcatb.2010.05.004.

22. Carriazo JG, Guelou E, Barrault J, Tatibouet JM, Moreno S. Catalytic wet peroxide oxidation of phenol over Al-Cu or Al-Fe modified clays. Applied Clay Science. 2003;22:303-308. Available from: https://doi.org/10.1016/S0169-1317(03)00124-8.

23. Sanabria N, Alvarez A, Molina R, Moreno S. Synthesis of pillared bentonite starting from the Al-Fe polymeric precursor in solid state and its catalytic evaluation in the phenol oxidation reaction. Catalysis Today. 2008;(133-135):530-533. Available from: https://doi.org/10.1016/j.cattod.2007.12.082. 